\title{
Productivity Evaluation for Long Horizontal Well Test in Deep- Water Faulted Sandstone Reservoir
}

\author{
Zhiwang Yuan $\mathbb{D}^{1,2}$ Li Yang, ${ }^{2}$ Yingchun Zhang, ${ }^{2}$ Rui Duan, ${ }^{2}$ Xu Zhang, ${ }^{2}$ Yihua Gao, \\ and Baoquan Yang ${ }^{2}$ \\ ${ }^{1}$ School of Energy Resources, China University of Geosciences (Beijing), Beijing 100083, China \\ ${ }^{2}$ CNOOC Research Institute Co., Ltd., Beijing 100028, China \\ Correspondence should be addressed to Zhiwang Yuan; shiyouxuezi@126.com
}

Received 22 July 2020; Revised 23 August 2020; Accepted 2 September 2020; Published 22 September 2020

Academic Editor: Guanglong Sheng

Copyright ( 2020 Zhiwang Yuan et al. This is an open access article distributed under the Creative Commons Attribution License, which permits unrestricted use, distribution, and reproduction in any medium, provided the original work is properly cited.

\begin{abstract}
For deep-water faulted sandstone reservoirs, the general practice is to design long horizontal wells improving well productivity. During the project implementation stage, well tests are performed on all drilled wells to evaluate well productivity accurately. Furthermore, multisize chokes are often utilized in a shorten test time for loosen formation, high test cost, and high well productivity. Nevertheless, the conventional productivity evaluation approach cannot accurately evaluate the well test productivity and has difficulty in determining the underneath pattern. As a result, the objective of this paper is to determine a productivity evaluation method for multisize chokes long horizontal well test in deep-water faulted sandstone reservoir. This approach introduces a productivity model for long horizontal wells in faulted sandstone reservoir. It also includes the determination of steady-state test time and the productivity evaluation method for multisize chokes. In this paper, the EGINA Oilfield, a deep-water faulted sandstone reservoir, located in West Africa was chosen as the research target. Based on Renard and Dupuy's steady-state equation, the relationship between the productivity index per meter and the length of horizontal section was derived. Consequently, this relationship is used to determine the productivity pattern for long horizontal wells with the same geological features, which can provide more accurate productivity evaluations for tested wells and forecast the well productivity for untested wells. After implementing this approach on the EGINA Oilfield, the determined relationship is capable to accurately evaluate the test productivity for long horizontal wells in reservoirs with similar characteristics and assist in examination and treatment for horizontal wells with abnormal productivity.
\end{abstract}

\section{Introduction}

Since the 1990s, deep-water turbidite sandstone reservoir becomes a hotspot for oil and gas exploration and development. Major oil and gas deep-water turbidite reservoirs have been found in places such as the Gulf of Mexico Basin in North America, the Campos Basin in South America, the Niger Delta in West Africa, and the South China Sea [1].

The drilling and well completion cost for a production well in deep-water oilfields is nearly 100 million US dollars. As a result, the general strategy in the development of deep-water oilfields is to drill less well and maintain a higher plateau production rate. For deep-water faulted oilfields, the general practice is to design long horizontal wells improving well productivity. During the project implementation stage, well tests are performed on all drilled wells to evaluate well productivity accurately. Thus, subsequent measurements can be taken if the well test productivity is lower than expected. Considering the loosen reservoir formation and high well productivity, multisize chokes were adopted to prevent sand production during the test process. Simultaneously, the well test time is usually kept in a very short due to test cost, crude oil storage, and other factors, which makes well productivity evaluation difficult. Therefore, the conventional productivity evaluation approach cannot accurately evaluate the well test productivity and has difficulty in determining the productivity pattern. Thus, it is necessary to establish an accurate productivity evaluation method for long horizontal wells using multisize chokes in deep-water faulted sandstone reservoirs. Currently, the Lower Congo and the 


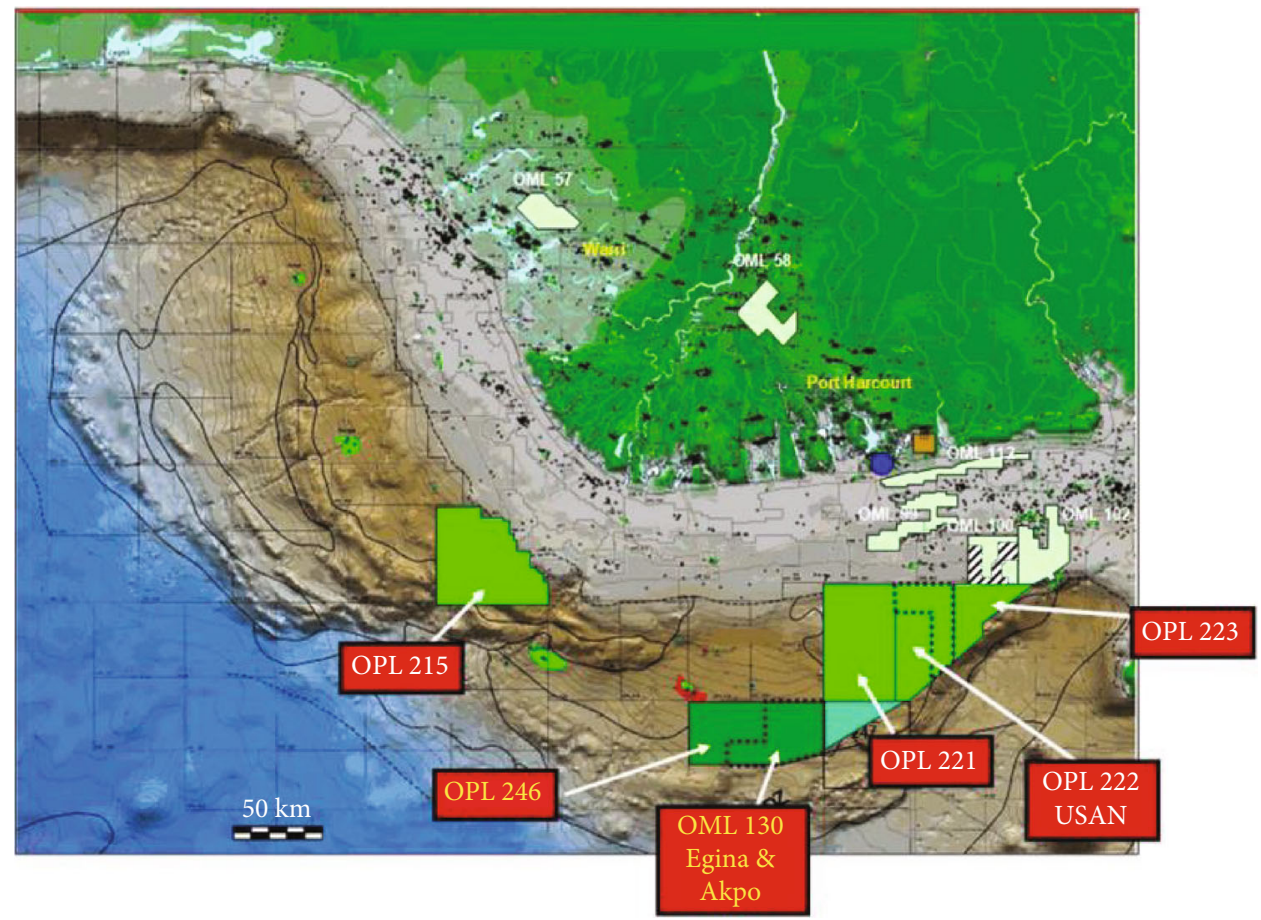

FIGURE 1: EGINA field location [18].

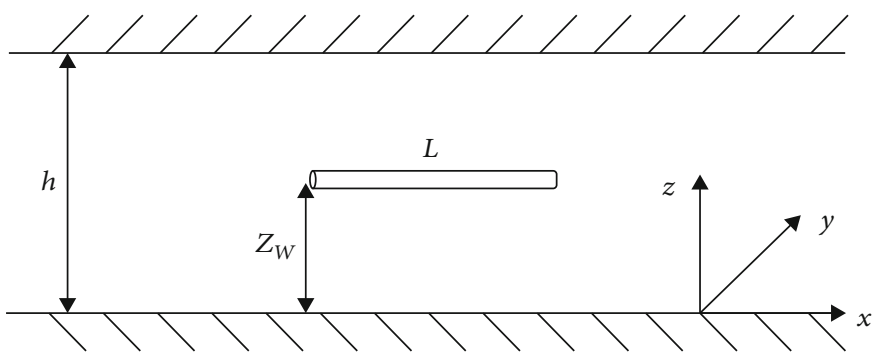

FIgure 2: Physical model of a horizontal well in faulted sandstone reservoir.

Niger Delta Basin are the attraction points for the exploration and development of deep-water turbidite reservoirs. They have been studied by petroleum engineers all over the world, which include their deposition mechanism [2, 3], deposition model $[3,4]$, deposition characteristics, evolution pattern [1], channel distribution and configuration characteristics [5-7], connectivity mode and connectivity $[8,9]$, and water-cut rising mechanism and water injection optimization method [10]. In addition, the results of oil well productivity evaluation are mainly concentrated in the time correction coefficient [11-13], interlayer interference coefficient [14], and equivalent test time [15] in the shallow water oilfields, while in deep-water faulted sandstone reservoirs, the test productivity evaluation is limited in aspect of the productivity test process and on-site operations [16]. There are only few studies on the productivity evaluation method with multisize chokes for long horizontal wells.

The EGINA Oilfield, a deep-water faulted sandstone reservoir, located in West Africa was evaluated in this paper. A productivity evaluation approach was established for long horizontal wells with multisize chokes in deep- water faulted sandstone reservoirs. The method is composed of the establishment of productivity model for long horizontal wells in faulted sandstone reservoirs, the determination of steady-state test time with multisize chokes, and the productivity evaluation method with multisize chokes. Based on Renard and Dupuy's steady-state equation, the relationship between the productivity index per meter and the length of horizontal section was determined, and the pattern for test productivity in long horizontal wells with the similar geological features is derived. This finding can assist better understanding to the productivity evaluation for tested wells and forecast the well productivity for untested wells. By practicing in the EGINA Oilfield, the productivity evaluation approach and productivity pattern are proven to be reliable.

\section{EGINA Oilfield Overview}

The EGINA Oilfield is located in the deep-water contract area of OMLl130 in southern Nigeria, West Africa, about $160 \mathrm{~km}$ away from the Port Harcourt in the north (see Figure 1). The oilfield water depth is ranging from 1150 to 


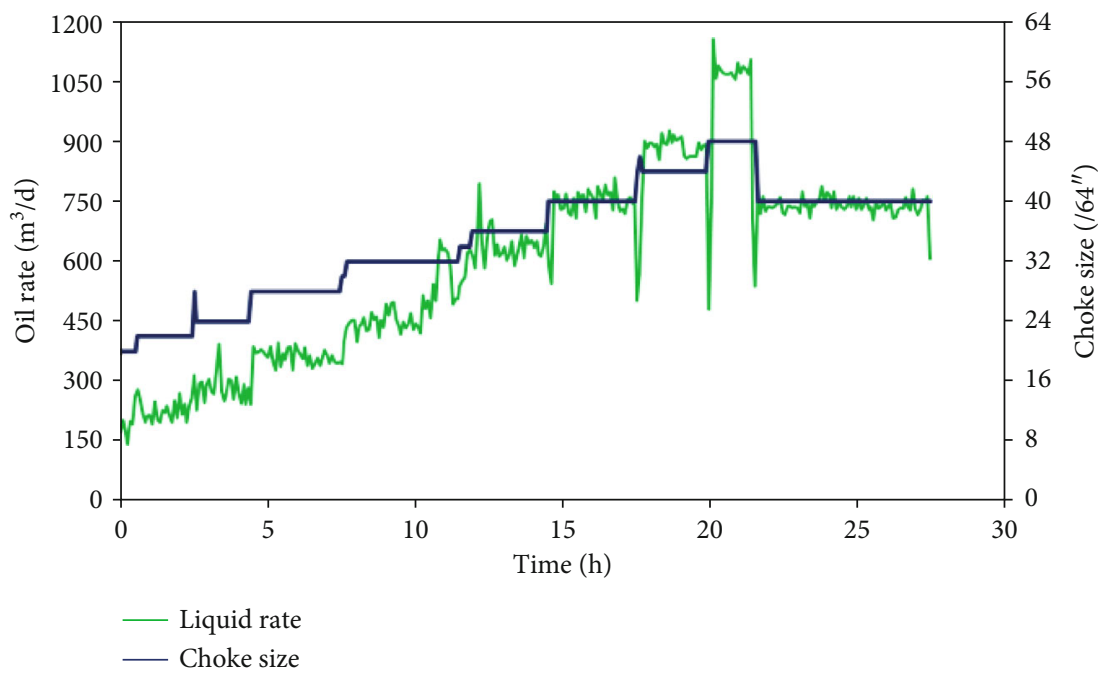

Figure 3: P-4 productivity test curve.
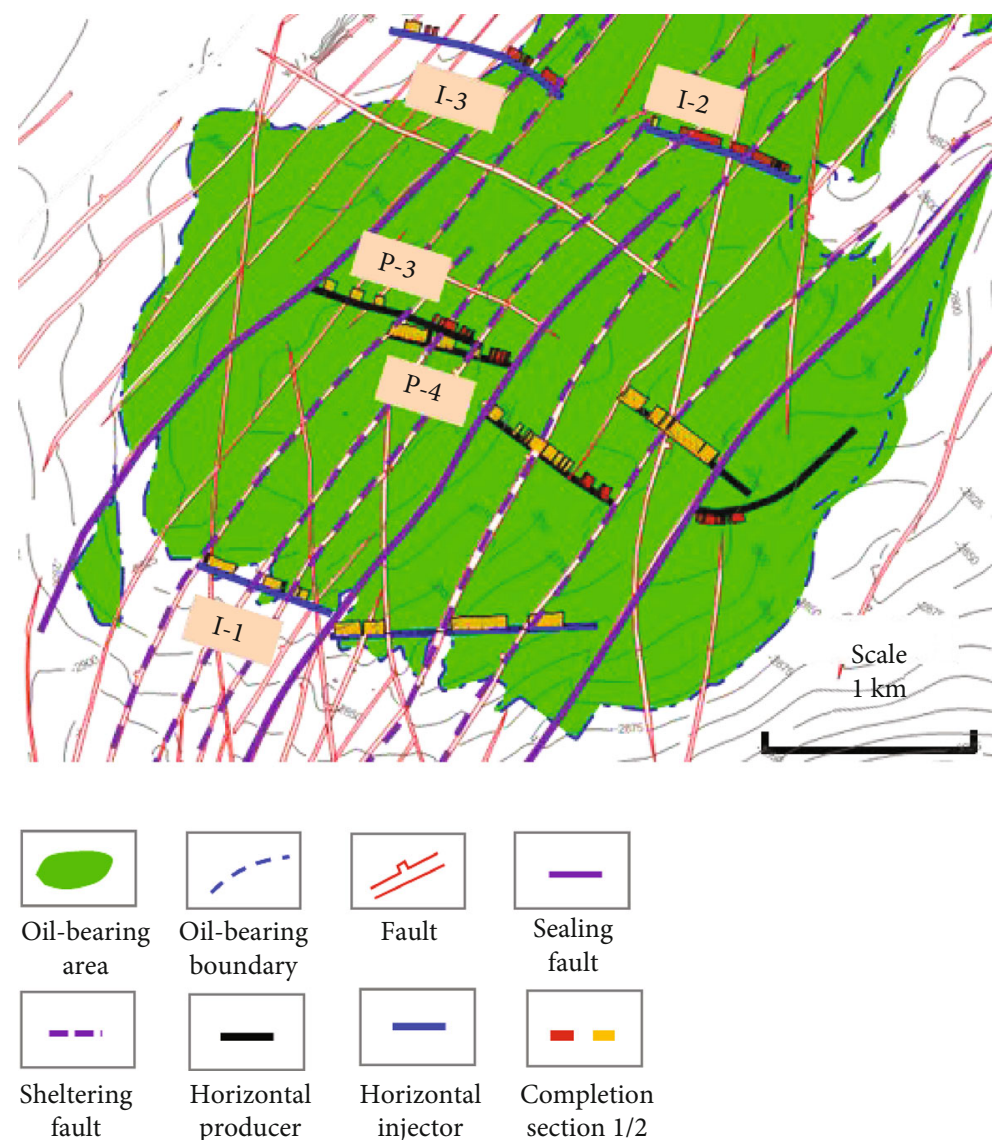

FIgURe 4: Well location of P-4.

$1750 \mathrm{~m}[16,17]$. It is operated by the TOTAL on behalf of the Nigerian National Petroleum Corporation (NNPC-Nigeria), the South Atlantic Petroleum Limited (SAPETRO-Nigeria), the PETROBRAS (Brazil), and the China National Offshore Oil Corporation (CNOOC China).

The EGINA Oilfield is a faulted anticline with complicated geological characters. The sedimentary facies of the res- ervoir is deep-water turbidite fan, and the lithology of the reservoir is fine-coarse sandstone which is mainly composed by quartz and feldspar. The reservoir is shallow buried, loose cemented, and weak compacted leading to medium-high porosity and high permeability. Primary intergranular pore forms the main reservoir spaces. The formation fluid is medium oil with low viscosity. 


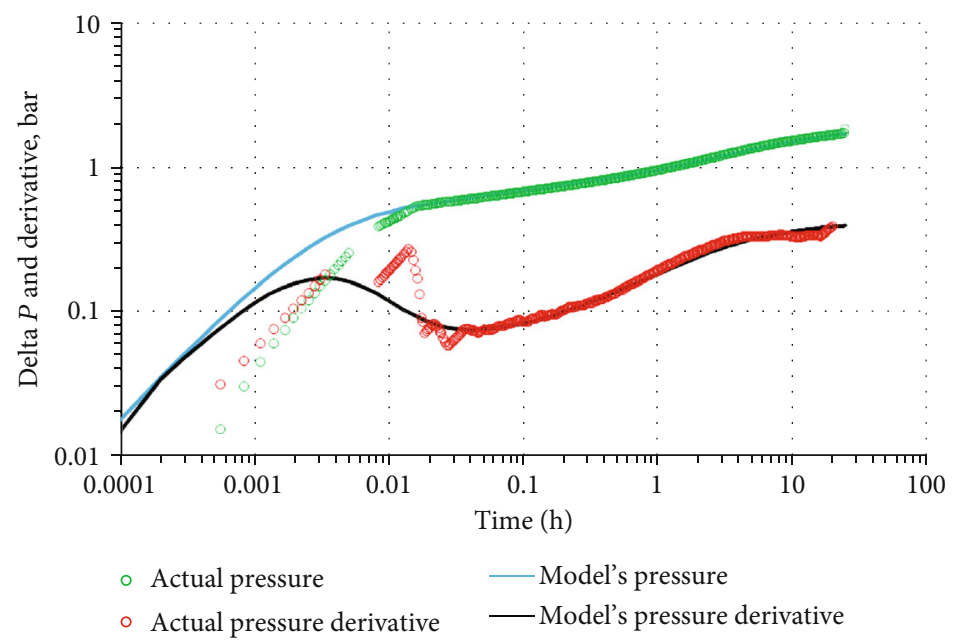

Figure 5: Interpretation chart of P-4 pressure buildup.

The EGINA Oilfield is developed using subsea wellhead and injection manifolds connected to an FPSO. The production has commenced from December 2018.

\section{Purpose and Procedure of Productivity Well Test for Long Horizontal Well in Deep-Water Sandstone Oilfield}

3.1. Test Purpose. The main purpose of the oil well productivity test is to:

(1) The first purpose is removing completion fluids and breaking down the mud-cake into small chips which can pass through the screen. We need to clean the entire screen length down to low water cut prior to their tieback to the subsea manifolds and to the FPSO [16]

(2) Another purpose of the productivity test is to collect fluid samples and obtain well/reservoir dynamic parameters relating to reservoir characteristics and completion efficiency (KH, skin, flow boundary, and production index), which help to reduce the uncertainty of productivity and fluid properties in the early stage of oilfield production

To make sure the oil field is reaching the production plateau as expected, the productivity test and evaluation of each well are carried out after the well is drilled and before it commences production.

3.2. Test Procedure. The productivity test design is completed by a well test software. Based on the expected range of reservoir physical parameters, a variety of test schemes are designed, and the optimized scheme is selected to determine the durations of well cleaning up and pressure buildup.

Small variations exist between each well test scheme. For unconsolidated sandstone reservoir, in order to prevent sand production, the general productivity test procedure is as follows: increase the choke sizes step by step by $4 / 64^{\prime \prime}$ and increase the daily oil production by no more than specific drawdown (4 bar for frac-packs and 2 bar for SAS and ES) or $300 \mathrm{~m}^{3} / \mathrm{d}$. Before switching to the next choke size, the pressure of each choke size shall be kept stable for at least 2 hours, and sand production is monitored simultaneously [16].

\section{Productivity Evaluation Method of Long Horizontal Well Test in Faulted Sandstone Oilfield}

4.1. Productivity Model of Long Horizontal Wells in Faulted Sandstone Reservoirs with Different Boundaries. The assumptions are as follows: (1) the fluid in the formation is singlephase fluid with low compressibility; (2) the effect of gravity and capillary force is neglected; (3) the pressure in all parts of the formation is the initial reservoir pressure before the productivity well test; (4) the reservoir is homogeneous, and the fluid flow achieves Darcy seepage; and (5) the top and bottom boundaries of the formation are impermeable.

Figure 2 is a physical model of a horizontal well in a faulted sandstone reservoir. Assuming the reservoir thickness is $h$ and the horizontal well length of $L$ from the bottom boundary $Z_{W}$, the reservoir permeability in the $X$ direction is equal to ones in the $Y$ direction, which is $K_{X}=K_{Y}=K_{H}$. Under different boundary conditions, the expression of dimensionless bottom hole flowing pressure for horizontal wells without wellbore storage and skin with a fixed production rate $Q$ is $[19,20]$ :

$$
\overline{p_{D}}=\frac{\pi}{L_{D}} \int_{0}^{t_{D}} G_{\mathrm{xD}}\left(x_{D}, \tau\right) \cdot G_{\mathrm{yD}}\left(y_{D}, \tau\right) \cdot G_{\mathrm{zD}}\left(z_{D}, \tau\right) d \tau
$$

where $C_{D}$ is the dimensionless wellbore storage coefficient; $S$ is the skin factor; $\overline{p_{D}}$ is the under different boundaries conditions, dimensionless bottom hole flowing pressure for horizontal wells without wellbore storage, and skin with a fixed production rate $Q ; Q$ is the daily oil production rate, $\mathrm{m}^{3} / \mathrm{d} ; L_{D}$ is the dimensionless length of horizontal section 
for horizontal well; $t_{D}$ is the dimensionless time; $x_{D}, y_{D}$, and $z_{D}$ are the dimensionless coordinates in the $X$ direction, $Y$ direction, and $Z$ direction, respectively; and $G_{\mathrm{xD}}\left(x_{D}, \tau\right), G_{\mathrm{yD}}$ $\left(y_{D}, \tau\right)$, and $G_{z \mathrm{D}}\left(z_{D}, \tau\right)$ are the green function in the $X$ direction, $Y$ direction, and $Z$ direction, respectively;

Under different boundary conditions, $G_{\mathrm{xD}}, G_{\mathrm{yD}}$, and $G_{\mathrm{zD}}$ can be expressed as follows [19, 20]:

(1) Under different boundaries conditions, $G_{x D}\left(x_{D}, \tau\right)$ can be expressed as follows:

(i) Both boundaries are sealing in the $X$ direction

$$
\begin{aligned}
G_{\mathrm{xD}}= & \frac{2 L_{D}}{x_{\mathrm{eD}}}\left[1+2 \sum_{n=1}^{\infty} \frac{1}{n} \exp \left(-\frac{n^{2} \pi^{2} t_{D}}{x_{\mathrm{eD}}^{2}}\right) \sin \left(\frac{L_{D}}{x_{\mathrm{eD}}}\right) \cos \right. \\
& \left.\cdot\left(\frac{n \pi x_{\mathrm{wD}}}{y_{\mathrm{eD}}}\right) \cos \left(\frac{n \pi x_{D}}{x_{\mathrm{eD}}}\right)\right] .
\end{aligned}
$$

(ii) Both boundaries are constant pressure in the $X$ direction

$$
\begin{aligned}
G_{\mathrm{xD}}= & \frac{4}{\pi} \sum_{n=1}^{\infty}\left[\frac{1}{n} \exp \left(-\frac{n^{2} \pi^{2} t_{D}}{x_{\mathrm{eD}}^{2}}\right) \sin \left(\frac{n \pi x_{\mathrm{wD}}}{x_{\mathrm{eD}}}\right) \sin \right. \\
& \left.\cdot\left(\frac{n \pi L_{D}}{x_{\mathrm{eD}}}\right) \sin \left(\frac{n \pi x_{D}}{x_{\mathrm{eD}}}\right)\right] .
\end{aligned}
$$

(iii) Mixed boundaries in $X$ direction(sealing at $x_{D}=0$, constant at $x_{D}=x_{\mathrm{eD}}$ )

$$
\begin{aligned}
G_{\mathrm{xD}}= & \frac{8}{\pi} \sum_{n=0}^{\infty}\left[\frac{1}{2 n+1} \exp \left[-\frac{(2 n+1)^{2} \pi^{2} t_{D}}{4 x_{\mathrm{eD}}^{2}}\right] \sin \left[\frac{(2 n+1) L_{D}}{x_{\mathrm{eD}}}\right] \cos \right. \\
& \left.\cdot\left[\frac{(2 n+1) \pi x_{D}}{2 x_{\mathrm{eD}}}\right] \cos \left[\frac{(2 n+1) \pi x_{\mathrm{wD}}}{2 x_{\mathrm{eD}}}\right]\right]
\end{aligned}
$$

(2) Under different boundaries conditions, $G_{\mathrm{yD}}\left(y_{D}, \tau\right)$ can be expressed as follows:

(i) Both boundaries are sealing in the $Y$ direction

$$
G_{\mathrm{yD}}=\frac{1}{y_{\mathrm{eD}}}\left[1+2 \sum_{n=1}^{\infty} \exp \left(-\frac{n^{2} \pi^{2} t_{D}}{y_{\mathrm{eD}}^{2}}\right) \cos ^{2}\left(\frac{n \pi y_{\mathrm{wD}}}{y_{\mathrm{eD}}}\right)\right] .
$$

(ii) Both boundaries are constant pressure in the $Y$ direction

$$
G_{\mathrm{yD}}=\frac{2}{y_{\mathrm{eD}}}\left[\sum_{n=1}^{\infty} \exp \left(-\frac{n^{2} \pi^{2} t_{D}}{y_{\mathrm{eD}}^{2}}\right) \sin ^{2}\left(\frac{n \pi x_{\mathrm{wD}}}{y_{\mathrm{eD}}}\right)\right] .
$$

(iii) Mixed boundaries in the $Y$ direction (sealing at $y_{D}$ $=0$, constant at $y_{D}=y_{\mathrm{eD}}$ )

$$
G_{\mathrm{yD}}=\frac{2}{y_{\mathrm{eD}}}\left[\sum_{n=1}^{\infty} \exp \left(-\frac{n^{2} \pi^{2} t_{D}}{y_{\mathrm{eD}}^{2}}\right) \cos ^{2}\left(\frac{n \pi x_{\mathrm{wD}}}{y_{\mathrm{eD}}}\right)\right] .
$$

(3) In the case of no gas cap and bottom water in the $Z$ direction, $G_{\mathrm{zD}}\left(z_{D}, \tau\right)$ can be expressed as follows:

$$
G_{\mathrm{zD}}=1+2 \sum_{n=1}^{\infty} \exp \left(-\frac{n^{2} \pi^{2} t_{D}}{h_{D}}\right) \cos ^{2}\left(\frac{n \pi z_{w}}{h}\right) .
$$

Considering wellbore storage and skin, the dimensionless bottom hole flowing pressure of horizontal well can be expressed as follows $[19,20]$ :

$$
\overline{p_{\mathrm{wD}}}=\frac{u \overline{p_{D}}+S / L_{D}}{u\left[1+C_{D} u\left(u \overline{p_{D}}+S / L_{D}\right)\right]},
$$

where $\overline{p_{\mathrm{wD}}}$ is the under different boundaries conditions, dimensionless bottom hole flowing pressure for horizontal wells with wellbore storage, and skin with a fixed production rate $Q$ in the Laplace space and $u$ is the Laplace transformation constant.

The Laplace numerical inversion of equation (9) is carried out to obtain the relationship between bottom hole flowing pressure and time, which can predict the productivity of long horizontal well with time in faulted sandstone reservoir under different boundary conditions.

4.2. Steady-State Time Determination of Multisize Chokes Test in Long Horizontal Well. For the well test with multisize chokes, it is necessary to determine whether the producer is steady or pseudo steady-state at all choke sizes and therefore select the appropriate methods to evaluate the test productivity. For a complex faulted sandstone reservoir with closed boundaries, a mathematical model can be established based on the reservoir parameters interpreted from the producer's pressure buildup curve and 


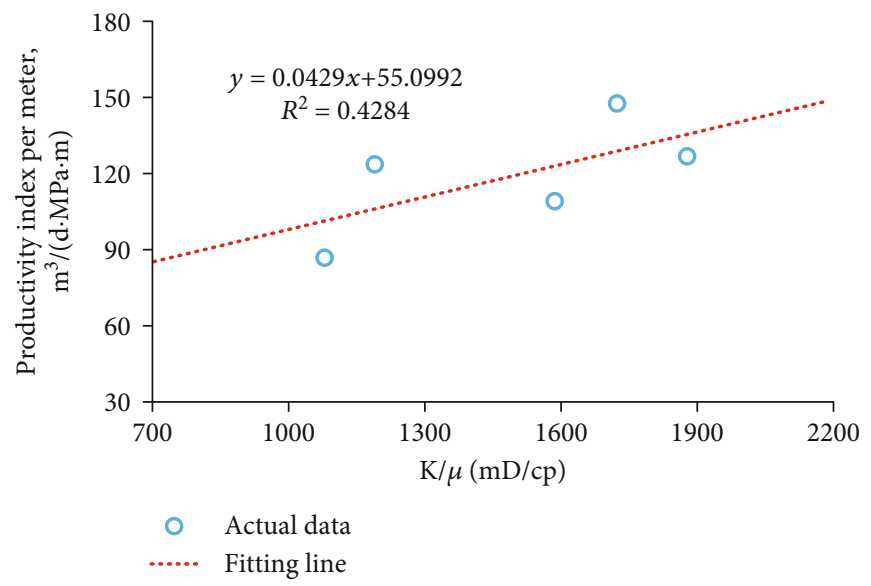

FIgURE 6: Relationship between transient productivity index per meter and mobility.

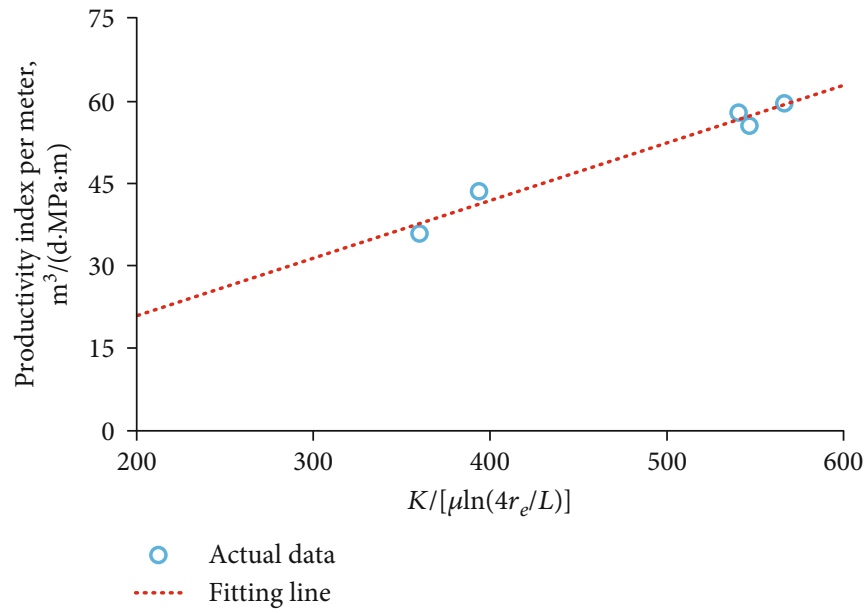

Figure 7: Relationship between steady productivity index per meter and $K /\left[\mu \ln \left(4 r_{e} / L\right)\right]$.

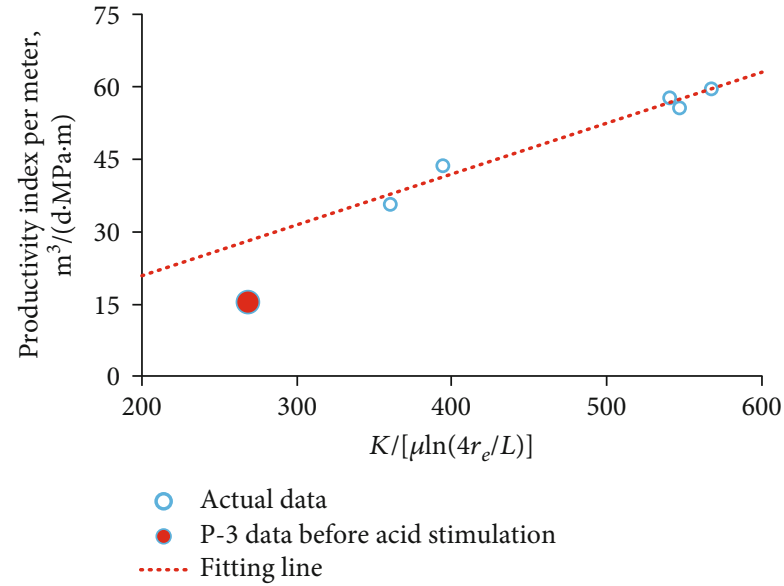

FIgURe 8: Productivity index per meter evaluation of P-3 before acid stimulation. the distribution characteristics of the reservoir and faults. Then, by simulating the well productivity test, the required time to reach the steady-state can be calculated.

4.3. Productivity Evaluation Method of Multisize Chokes Test in Long Horizontal Well Test. If well test with multiple choke sizes reach stable or pseudo steady-state, the data of these choke sizes can be used to derive the relationship between the bottom hole flowing pressure and the production rate. From equation (10), the reciprocal of the linear gradient is the productivity index of the test well.

$$
p_{w}=p_{e}-\frac{q}{J_{h}}
$$

where $p_{w}$ is the bottom hole flowing pressure, $\mathrm{MPa} ; p_{e}$ is the formation pressure, $\mathrm{MPa} q q$ is the daily oil production, $\mathrm{m}^{3} / \mathrm{d}$; and $J_{h}$ is the productivity index of horizontal well, $\mathrm{m}^{3} / \mathrm{d} / \mathrm{MPa}$.

If the well tests with multiple choke sizes do not reach stable or pseudo steady-state, the test data of last choke size is used to calculate the transient productivity index, and the 


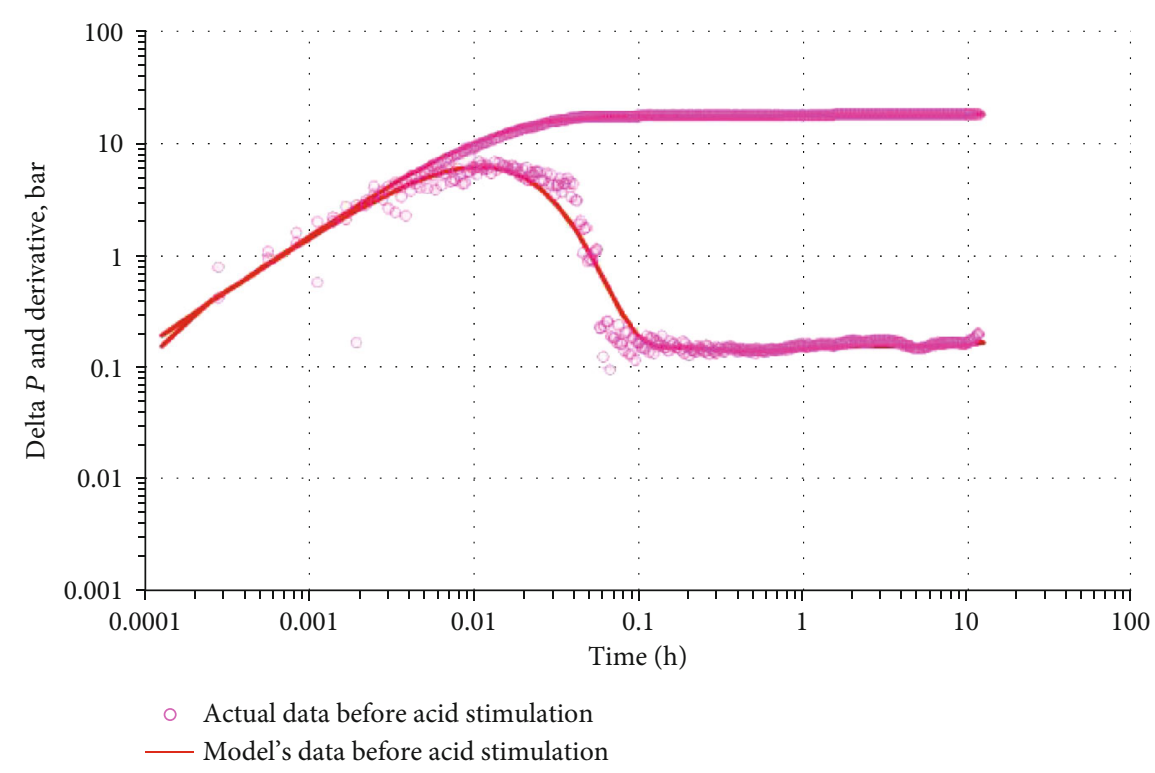

FIGURE 9: Interpretation chart of P-3 pressure buildup before acid stimulation.

equivalent test time can be determined by equation (11) [15]. If the evaluated equivalent time does not reach stable or pseudo steady-state, the time correction coefficient, the productivity index at stable or pseudo steady-state divided by the transient test productivity index, can be obtained by the mathematical model established in Section 4.1. As a result, the productivity index at the stable or pseudo steady-state is obtained.

$$
t_{\mathrm{pe}}=\frac{N_{p}}{q_{h}},
$$

where $N_{p}$ is the well test cumulative oil production, $\mathrm{m}^{3} ; q_{h}$ is the daily oil production of last choke size, $\mathrm{m}^{3} / \mathrm{d}$; and $t_{\mathrm{pe}}$ is the equivalent test time, $d$.

\section{Productivity Evaluation Method for Well Test Productivity Pattern of Long Horizontal Wells}

To derive the productivity evaluation approach for test productivity pattern of long horizontal well, Renard and Dupuy's equation ${ }^{[21]}$ is analyzed, as shown in equation (12):

$$
J_{h}=\frac{q}{P_{e}-P_{w}}=\frac{1}{(\mu / 0.543 k h) \ln \left(\left(a+\sqrt{a^{2}-(L / 2)^{2}}\right) /(L / 2)\right)+(\mu / 0.543 k L) \ln \left(h / 2 \pi r_{w}\right)}
$$

we set

$$
a=\frac{L}{2}\left[\frac{1}{2}+\sqrt{\frac{1}{4}+\left(\frac{2 r_{e}}{L}\right)^{4}}\right]^{0.5}
$$

where $\mu$ is viscosity of the formation crude oil, $\mathrm{cp} ; k$ is the reservoir permeability, $\mathrm{mD} ; h$ is the reservoir thickness, $\mathrm{m} ; L$ is the length of the horizontal section, $\mathrm{m} ; r_{w}$ is the wellbore radius, $\mathrm{m} ; r_{e}$ is the drainage radius, $\mathrm{m}$; and $a, b, c$, and $d$ are constant.

$$
\begin{aligned}
& \text { We set } b=(\mu / 0.543 k h) \ln \left(a+\sqrt{a^{2}-(L / 2)^{2}} / L / 2\right) \\
& c=(\mu / 0.543 k L) \ln \left(h / 2 \pi r_{w}\right), \text { and } d=a+\sqrt{a^{2}-(L / 2)^{2}} / L / 2, \\
& \text { from equation }(13): \\
& d= \frac{(L / 2)\left[\sqrt{1 / 4+\left(2 r_{e} / L\right)^{4}}+1 / 2\right]^{0.5}+(L / 2)\left[\sqrt{1 / 4+\left(2 r_{e} / L\right)^{4}}-1 / 2\right]^{0.5}}{L / 2} \\
&= {\left[\sqrt{\frac{1}{4}+\left(\frac{2 r_{e}}{L}\right)^{4}}+\frac{1}{2}\right]^{0.5}+\left[\sqrt{\frac{1}{4}+\left(\frac{2 r_{e}}{L}\right)^{4}}-\frac{1}{2}\right]^{0.5} . }
\end{aligned}
$$




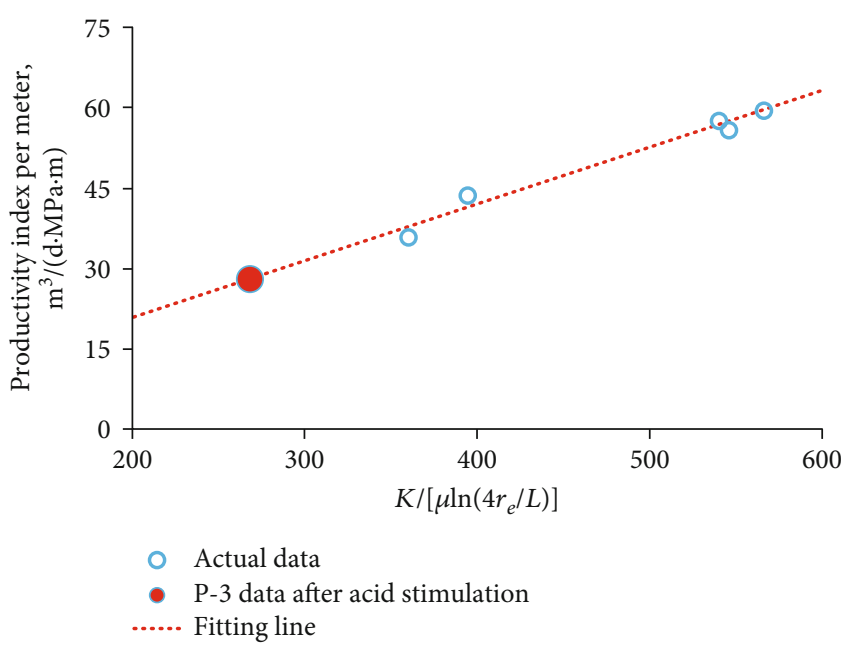

Figure 10: Productivity index per meter evaluation of P-3 after acid stimulation.

Square the both sides of equation (14):

$$
\begin{aligned}
d^{2} & =2 \sqrt{\frac{1}{4}+\left(\frac{2 r_{e}}{L}\right)^{4}}+2 \sqrt{\left(\frac{2 r_{e}}{L}\right)^{4}} \\
& =2 \sqrt{\frac{1}{4}+\left(\frac{2 r_{e}}{L}\right)^{4}}+2\left(\frac{2 r_{e}}{L}\right)^{2} \approx 4\left(\frac{2 r_{e}}{L}\right)^{2} .
\end{aligned}
$$

From equation (15):

$$
\begin{gathered}
d \approx \frac{4 r_{e}}{L}, \\
\frac{b}{c}=\frac{L}{h}\left(\ln \frac{a+\sqrt{a^{2}-(L / 2)^{2}}}{L / 2} / \ln \frac{h}{2 \pi r_{w}}\right) .
\end{gathered}
$$

Substituting equation (16) into equation (17):

$$
\frac{b}{c}=\frac{L}{h}\left(\frac{\ln 4 r_{e} / L}{\ln h / 2 \pi r_{w}}\right) .
$$

For long horizontal wells, the difference between $\ln \left(4 r_{e} / L\right)$ and $\ln \left(h /\left(2 \pi r_{w}\right)\right)$ is small, while the length $L$ of horizontal wells is far greater than the reservoir thickness $h$; therefore:

$$
\frac{b}{c}=\frac{L}{h}\left(\frac{\ln 4 r_{e} / L}{\ln h / 2 \pi r_{w}}\right)>>1 .
$$

Thus, constant $c$ can be neglected. Substituting equation (16) into equation (12):

$$
J_{\mathrm{om}}=\frac{J_{h}}{h}=\frac{q}{\left(P_{e}-P_{w}\right) h} \approx \frac{0.543 k}{\mu \ln \left(4 r_{e} / L\right)},
$$

where $J_{\text {om }}$ is the productivity index per meter, $\mathrm{m}^{3} / \mathrm{d} / \mathrm{MPa}$.
Equation (20) underlines the linear relationship between $J_{\text {om }}$ and $K /\left[\mu \ln \left(4 r_{\mathrm{e}} / L\right)\right]$. Based on this relationship, the test productivity pattern of long horizontal oil wells with the similar geological features is determined, which can guide the productivity prediction of untested oil wells and improve the evaluation for the tested oil wells.

\section{Applications and Discussions}

The EGINA Oilfield adopts the development strategy "less wells with high production rate.” All drilled oil wells are conducted with the productivity test to remove completion fluids and ensure the accuracy of the test productivity. Due to the high well productivity and loosen reservoir formations, the test procedure increasing the test choke step by step (Section 3.2) is adopted to prevent sand production during the productivity test. At the same time, high test cost in deep-water oilfield is considered as the well test time is kept very short. For instance, the oil well P-4 was tested using 10 different choke sizes with increasing pattern. The maximum daily oil production was $1150 \mathrm{~m}^{3} / \mathrm{d}$, and a total test time was 27.4 hours, as shown in Figure 3.

\subsection{Well Test Productivity Evaluation with Multisize Chokes for P-4 Well}

6.1.1. Determination of Steady-State Time for P-4 Well. To evaluate the well test productivity of the P-4 well, the first priority is to confirm whether the tests at all choke sizes have reached the steady or pseudo steady-state to select the appropriate method. P-4 is a horizontal well in a complex faulted sandstone reservoir; the well location map is illustrated in Figure 4. The mathematical model is established based on the reservoir parameters derived from the pressure buildup curve of P-4 (see Figure 5) and faults distribution characteristics. Subsequently, this model is used to simulate the procedure of well productivity test, and the time calculated for the well to reach the steady-state is 51 days.

6.1.2. Productivity Evaluation with Multisize Chokes for P-4 Well. From Figure 3, the ten choke sizes tested at P-4 well have not reached steady-state. The tested data of final choke size is used to calculate the transient productivity, and the transient productivity index of $\mathrm{P}-4$ is $3666 \mathrm{~m}^{3} / \mathrm{d} / \mathrm{MPa}$. The equivalent test time calculated by equation (11) is 9.7 hours, combined with the productivity model in the previous Section 4.3; the time correction coefficient is 0.41 , and the steady-state productivity index is $1503 \mathrm{~m}^{3} / \mathrm{d} / \mathrm{MPa}$.

6.2. Pattern of Productivity Evaluation for Long Horizontal Wells in Faulted Sandstone Oilfields. To derive the pattern of well test productivity for long horizontal wells in faulted sandstone reservoir, horizontal wells with similar geological features were screened out, and the relationship between the transient productivity index and mobility was analyzed. Based on Figure 6, the linear relationship is not obvious. However, the method introduced in this paper is able to determine the productivity index of each well at steadystate. As a result, the relationship between productivity index at steady-state and $K /\left[\mu \ln \left(4 r_{e} / L\right)\right]$ can be found based on 


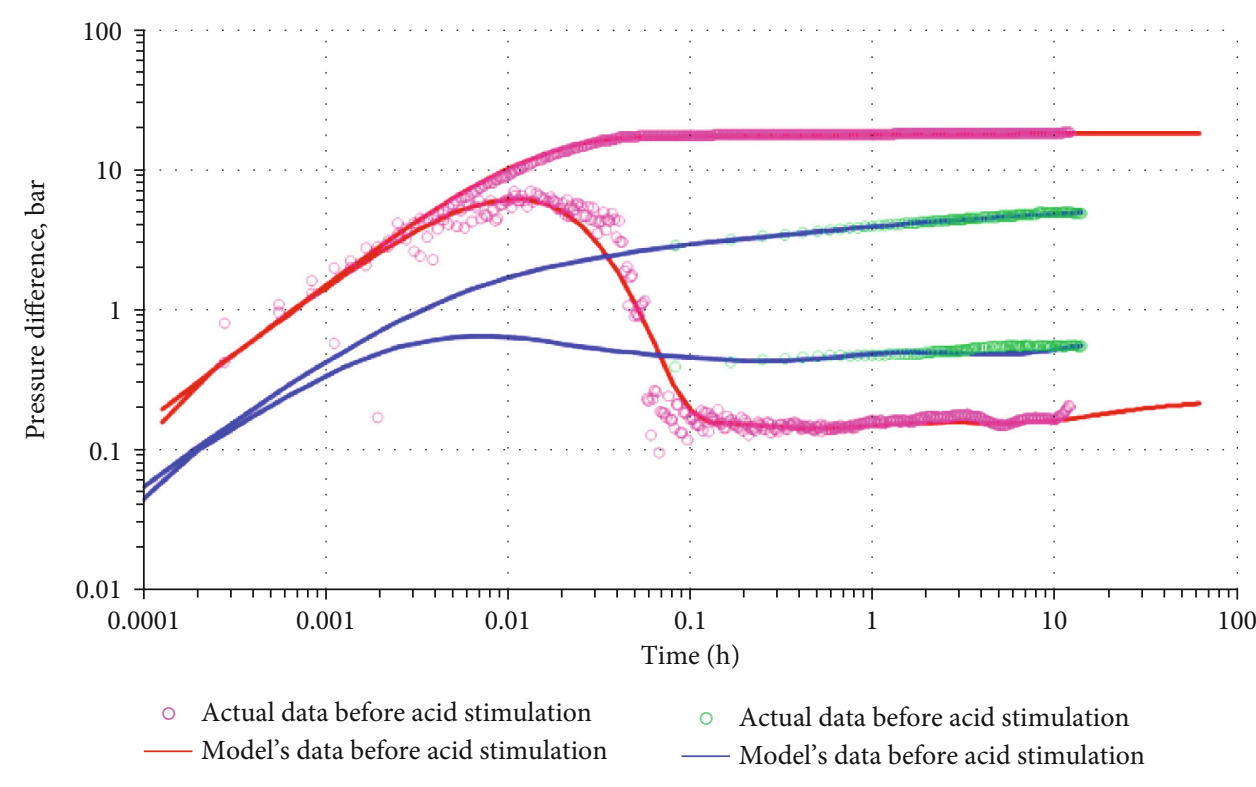

FIgURE 11: The pressure buildup interpretation comparison of P-3 before and after acid stimulation.

equation (20), which is a nicely fit (see Figure 7). Therefore, this approach can evaluate the pattern of tested well productivity and predict the productivity of untested wells.

\subsection{Examination and Treatment of Horizontal Wells with Abnormal Test Productivity}

6.3.1. Examination of Horizontal Wells with Abnormal Well Test Productivity. To ensure the productivity of horizontal wells as expected before production commencement, an examination of the reliability for the test productivity becomes a necessary step. To begin with, the method introduced in Section 4 is utilized to evaluate the well test productivity of tested wells. Then, the reliability of test result is analyzed by the productivity trend of tested horizontal wells mentioned in Section 5. If a well with abnormal test productivity exists, it will be suggested to take corresponding measures. For example, after productivity evaluation of well P3 , it is compared with relationship between productivity index per meter of horizontal wells at steady-state and $K /[\mu$ $\left.\ln \left(4 r_{\mathrm{e}} / L\right)\right]$. Based on Figure 8, the tested productivity of P3 is significantly lower than other wells. From the pressure buildup interpretation of P-3 (see Figure 9), its skin factor is 34 , which is obviously too high. Thus, serious reservoir pollution near the well bore is suggested to be the cause of the high skin factor.

6.3.2. Treatment of Horizontal Wells with Abnormal Well Productivity. Acidizing treatment was carried out to remove the reservoir pollution near the wellbore of P-3. The productivity after acidizing treatment is compared with the relationship between the productivity index per meter of tested horizontal wells at steady-state and the $K /\left[\mu \ln \left(4 r_{e} / L\right)\right]$. From Figure 10, the productivity is on the trend line, and the skin factor becomes 0.20 (see Figure 11), indicating that the pollution near the wellbore has been removed.

\section{Conclusion}

(1) A productivity evaluation method for multisize chokes long horizontal wells in deep-water faulted sandstone reservoirs is established to consider loosen reservoir formation, high well productivity, and short well test time, which can determine the productivity of long horizontal wells at steady-state

(2) Based on Renard and Dupuy's steady-state equation, the relationship between the productivity index per meter and the length of horizontal section was derived. The trend line of test productivity for long horizontal wells under the same geological features is obtained, which can guide to a more accurate productivity evaluation for tested wells and forecast the productivity for untested wells

(3) Based on the field practice in the EGINA Oilfield, productivity evaluation and pattern derived from the tested results at steady-state can suggest appropriate treatment method for horizontal wells with abnormal productivity. This method is proven to be reliable and can evaluate the test productivity of long horizontal wells in similar deep-water faulted sandstone reservoirs

\section{Data Availability}

The data used to support the findings of this study are available from the corresponding author upon request.

\section{Conflicts of Interest}

The authors declare no conflict of interest. 


\section{Authors' Contributions}

Conceptualization was done by Zhiwang Yuan and Li Yang; methodology was done by Zhiwang Yuan; validation was done by Zhiwang Yuan and Yingchun Zhang; writing the original draft preparation was done by Zhiwang Yuan; writing the review and editing were done by Zhiwang Yuan, Rui Duan, Xu Zhang, and Yihua Gao.

\section{Acknowledgments}

The authors are indebted to Baoquan Yang for sharing their meaningful points and discussions. This research was funded by the National Science and Technology Major Project (grant number 2017ZX05032-004).

\section{References}

[1] L. Xinying, "Depositional characteristics and evolution of the Tertiary deep-water fan in west Africa," Journal of Northeast Petroleum University, vol. 37, no. 3, pp. 24-31, 2013.

[2] L. Li, Y. M. Wang, Z. C. Huang, and L. M. Zhang, "Study on sequence stratigraphy and seismic facies in deep-water Niger Delta," Acta Sedimentological Sinica, vol. 26, no. 3, pp. 407416, 2008.

[3] L. Ming, W. Ying, and C. Ying, "A discussion on origins of submarine fan deposition model and its exploration significance in Nigeria deep-water area," China Offshore Oil and Gas, vol. 20, no. 4, pp. 275-282, 2008.

[4] B. Fanqing, Z. Xu, and C. Guoning, "Gravity flow depositional mode and reservoir characteristics of Niger Delta Basin: taking AKPO Oilfield as an example," Journal of Xi'an Shiyou University(Natural Science Edition), vol. 32, no. 1, pp. 64-70, 2017.

[5] Z. Xiaoming, W. Shenghe, and L. Li, "Sedimentary architecture model of deep-water channel complexes in slope area of West Africa," Journal of China University of Petroleum (Edition of Natural Science), vol. 36, no. 6, pp. 1-5, 2012.

[6] Z. Xiaoming, W. Shenghe, and L. Li, "Characterization of reservoir architectures for Neogene Deepwater turbidity channels of AKPO oilfield in Niger Delta basin," Acta Petrolei Sinica, vol. 33, no. 6, pp. 1049-1058, 2012.

[7] W. Zhang, D. U. Taizhong, L. I. Zhiqiang, Y. Shujin, L. Yu, and $\mathrm{X}$. Huaming, "Application of multi-point geostatistics in deepwater turbidity channel simulation: a case study of Plutonio oilfield in Angola," Petroleum Exploration and Development, vol. 43, no. 3, pp. 403-410, 2016.

[8] C. Xiao, B. Fanqing, W. Hao, C. Guoning, and Z. Xu, "Characterization of connectivity models of deepwater turbidite compound channels in West Africa," Journal of Southwest Petroleum University (Science \& Technology Edition), vol. 40, no. 6, pp. 35-46, 2018.

[9] B. U. Fanqing, Z. H. Yukun, and Y. A. Baoquan, "Technique and application of fine connectivity characterization of composite deep water turbidite channels," Fault-Block Oil \& Gas Field, vol. 22, no. 3, pp. 309-313, 2015.

[10] Y. U. Zhiwang, Y. A. Baoquan, Y. A. Li et al., "Water-cut rising mechanism and optimized water injection technology for deepwater turbidite sandstone oilfield: a case study of AKPO Oilfield in Niger Delta Basin, West Africa," Petroleum Exploration and Development, vol. 45, no. 2, pp. 287-296, 2018.
[11] L. Bo, X. Luo, and L. Ying, "A new method to predict reasonable deliverability of individual wells in offshore heavy oilfields," China Offshore Oil and Gas, vol. 4, pp. 243-245, 2008.

[12] C. Hui, "A new method to determine calibration coefficient for oil-well test time," China Offshore Oil and Gas, vol. 22, no. 6, pp. 391-393, 2010.

[13] S. Yanghui, Y. Yuedong, L. Shujun, L. Yanhu, and F. Na, "Calculating method of the productivity correcting coefficient for the horizontal wells on offshore oilfield," Petroleum Geology \& Oilfield Development in Daqing, vol. 3, pp. 96-100, 2014.

[14] C. Hui, Y. Xiaoyan, Z. Zhanhua, H. Qin, and C. Dayong, "Application of a new quantitative interlayer interference characterization method in Kenli area, southern Bohai Sea," Special Oil and Gas Reservoirs, vol. 25, no. 4, pp. 91-94, 2018.

[15] D. R. Horner, Pressure build-up in wells, Proceedings of the 3rd World Petroleum Congress, Netherlands, 1951.

[16] C. Onyeanuna, "Field case deepwater development wells clean-up and test," in 2011 SPE Nigeria Annual International Conference and Exhibition, pp. 1-8, 2011.

[17] C. Okpalla, V. Chaloupka, R. Djenani et al., "EGINA deep water development completion success: one team working together setting new performance standards," in Society of Petroleum Engineers, 2019.

[18] K. Johnson, C. Morand, M. Williams et al., "EGINA deep water completion operations continuous improvement achieved by implementing process optimization practices," in Offshore Technology Conference, 2019.

[19] F. Du Kui and S. George, "Analysis of transient pressure response of horizontal wells in bounded reservoirs using derivative approach," SPE Formation Evaluation, vol. 9, no. 1, pp. 32-38, 1994.

[20] S. Al Rbeawi, "Transient pressure analysis of horizontal wells in a multiboundary system," American Journal of Engineering Research, vol. 4, p. 44, 2013.

[21] R. Gerard and J. M. Dupuy, "Formation damage effects on horizontal-well flow efficiency," Journal of Petroleum Technology, vol. 43, no. 7, pp. 786-869, 1991. 